九州大学学術情報リポジトリ

Kyushu University Institutional Repository

\title{
Studies on Dissolved Hydrogen Behavior in Autototrophic Culture of Alcaligenes eutrophus ATCC $17697^{\wedge} \mathrm{T}$
}

Takeshita, Toshihiro

Department of Food Science and Technology, Faculty of Agriculture, Kyushu University

Tanaka, Kenji

Department of Food Science and Technology, Faculty of Agriculture, Kyushu University

Ishizaki, Ayaaki

Department of Food Science and Technology, Faculty of Agriculture, Kyushu University

Stanbury, Peter F.

Department of Food Science and Technology, Faculty of Agriculture, Kyushu University

https://doi.org/10.5109/24037

出版情報: 九州大学大学院農学研究院紀要. 38 (1/2)，pp.55-64，1993-12. Kyushu University バージョン：

権利関係 : 


\title{
Studies on Dissolved Hydrogen Behavior in Autototrophic Culture of A lcaligenes eutrophus ATCC $17697^{\top}$
}

\author{
Toshihiro Takeshita, Kenji Tanaka, A yaaki I shizaki \\ and Peter F. Stanbury" \\ Department of Food Science and Technology, Faculty of Agriculture, \\ Kyushu University 46-09, Fukuoka 812, Japan \\ (Received June 30, 1993)
}

\begin{abstract}
The partial pressure of dissolved hydrogen was measured to investigate the behavior of dissolved hydrogen during the autotrophic growth of the hydrogen-oxidizing bacterium, Alcaligenes eutrophus ATCC $17697^{\mathrm{T}}$. A dissolved hydrogen sensor was constructed by modifying a Clark type dissolved oxygen probe. By using this sensor the overall volumetric coefficient of hydrogen mass transfer, $\left(K_{\mathrm{L}} a\right)_{\mathrm{H} 2}$, was determined in the culture system and compared with that of oxygen, $\left(K_{\mathrm{L}} a\right)_{\text {ozbiol. }}$. Good straight line relationships were demonstrated between $(1) \ln \left(K_{\mathrm{L}} a\right)_{\text {orbolol. }}$ and $\ln \left(K_{\mathrm{L}} a\right)_{\text {Ozsul. }}\left(K_{\mathrm{I}} a\right.$ for oxygen determined by sulphite oxidation) and $(2) \ln \left(K_{\mathrm{L}} a\right)_{\text {orbioi }}$. and $\ln \left(\mathrm{K}_{\mathrm{L}} \mathrm{a}\right)_{\mathrm{H} 2}$. The critical partial pressure for dissolved hydrogen was shown to be $11.6 \mathrm{kPa}$, while that for oxygen was 3.17 $\mathrm{kPa}$. The $K d$ (volumetric absorption coefficient) values for hydrogen and oxygen were determined from the respective $K_{\perp} a$ 's under a range of operating conditions and whereas the $K_{\llcorner} a$ values for hydrogen were greater than those for oxygen the $K d$ values were very similar.
\end{abstract}

\section{INTRODUCTION}

Poly- $\beta$ - hydroxybutyric acid (PHB) is a raw material for the manufacture of biodegradable plastics. The hydrogen-oxidizing bacterium, Alcaligenes eutrophus, accumulates various kinds of polyhydroxyalcanoates (Doi et al., 1988; Kunioka et al., 1989 ) and is capable of producing PHB from carbon dioxide autotrophically (Ishizaki and Tanaka, 1991). Microbial PHB production from carbon dioxide is an attractive process because it may help to solve two difficult environmental problems: the increase in carbon dioxide concentration in the atmosphere and plastic pollution.

We have developed a recycled-gas closed-circuit culture system for the production of PHB from high cell density cultures of $A$. eutrophus ATCC $17697^{\mathrm{T}}$ growing on carbon dioxide and hydrogen under aerobic conditions (Ishizaki and Tanaka, 1991; Ishizaki and Tanaka, 1990). However, there is an inherent danger of explosion associated with this process and it is vital that the composition of the gas phase is strictly controlled to ensure that the ratio of oxygen to hydrogen is not within the detonation range. According to the stoichiometry of this system (Ishizaki and Tanaka, 1991; Ishizaki and Tanaka, 1990) the ratio of $\mathrm{H}_{2}: \mathrm{O}_{2}: \mathrm{CO}_{2}$ required for cell growth is 21.36: 6.21: 4.09 and that for PHB accumulation is 33: 12: 4. Although this composition is within the detonation range, the composition of the gas phase in a fermentation would be determined by the relative mass transfer capacities of the different gasses, the critical concentration partial pressures of the dissolved gasses and the effect of the partial

*Visiting professor to Kyushu University (University of Hertfordshire, UK.) 
pressures of the individual gasses on the physiology of the organism. Thus, to determine the possible gas composition it is necessary to study the behavior of the substrate gasses in the culture system. The mass transfer kinetics and behavior of oxygen and carbon dioxide have been well documented (Ishizaki and Tanaka, 1991; Ishizaki and Tanaka, 1990; Ishizaki and Hirose, 1973; Ishizaki et al., 1973). However, although there are many reports measuring dissolved hydrogen concentration (Kodama et al., 1976; Shiegel and Ollis, 1984; Heinzle and Laffety, 1980; Pauss et al., 1990; Kuroda et al., 1991; Sweet et al., 1980; Niedrach and Stoddard, 1982; Kurosawa and Hagihara, 1986; Oki et al., 1979) very little data are available on the determination of the mass transfer kinetics of hydrogen and its behavior in a fermentor.

In this paper the development of a dessolved hydrogen sensor is reported and the kinetics of hydrogen mass transfer in the fermentation system compared with that of oxygen. The problem of obtaining high PHB productivity from hydrogen under safe operating conditions is also discussed.

\section{MATERIALS AND METHODS}

\section{Cultivation and analyses}

The strain, medium preparation and analytical methods were as previously reported (Ishizaki and Tanaka 1991; Ishizaki and Tanaka, 1990).

\section{Dissolved hydrogen sensor}

The dissolved hydrogen sensor is shown in Fig. 1 and was developed by modifying a

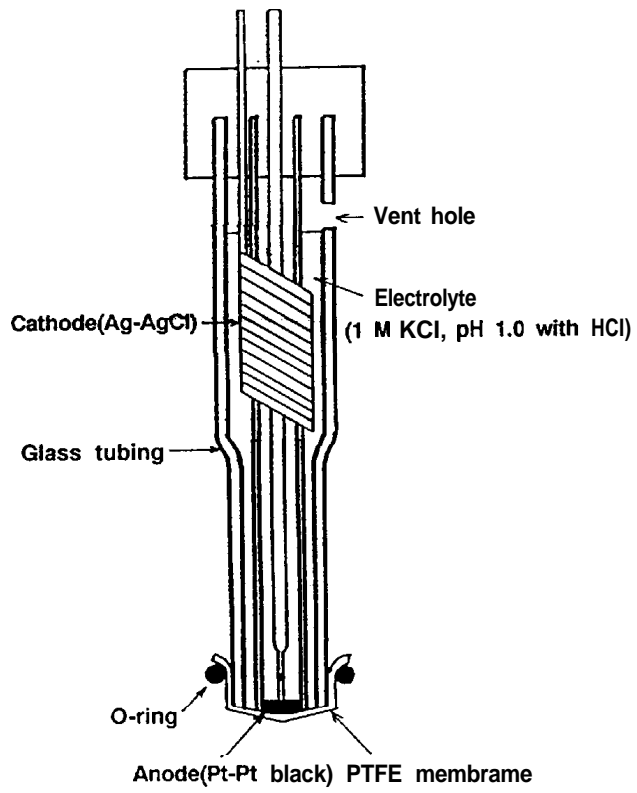

Fig. 1. Cross section view of the dissolved hydrogen sensor. 
Clark type oxygen sensor, DG-5P, $134 \mathrm{~mm}$ long and $10 \mathrm{~mm}$ diameter (Biott Co., Ltd., Tokyo), using a very similar method to that reported by previous workers (Niedrach and Stoddard, 1982; Kurosawa and Hagihara 1986). The sensor consisted of a silver/ silver chloride cathode and a platinum/platinum black anode with $1 \mathrm{M} \mathrm{KCl}(\mathrm{pH} 1.0$ with $\mathrm{HCl}$ ) as the internal electrolyte. To coat the spiral $\mathrm{Ag}$ electrode with $\mathrm{AgCl}$, the probe was filled with a $1 \mathrm{M} \mathrm{KC1}$ solution and electrolyzed at DC $10 \mathrm{~mA}$ for $1 \mathrm{~d}$ using a platinum plate as a counter electrode. The solution was then discarded and the inside of the probe rinsed with $1 \mathrm{M} \mathrm{KCl}$. Similarly, to coat the plane disc Pt electrode with platinum black (Pt black) the tip of the probe was dipped into a 3\% hydrogen hexachloroplatinate (IV) solution without lead acetate and was electrolyzed at DC 5.0 $\mathrm{V}$ for $1.5 \mathrm{~min}$ using a platinum plate as a counter electrode. The probe was then rinsed with $1 \mathrm{M} \mathrm{KCl}$. The tip of the sensor was covered with a $2.54 \mu \mathrm{m}$ thick polytetrafluoroethylene membrane which was fixed to the sensor with 3 O-rings (i.d. $3.7 \mathrm{~mm}$ and o.d. $7.5 \mathrm{~mm}$ ) and silicone lubricant SH-103 (TORAY DOW CORNING, Tokyo) as a sealing material. Finally, the sensor was filled with $1 \mathrm{M} \mathrm{KC1}$ electrolyte, the $\mathrm{pH}$ of which had been adjusted to 1.0 with $\mathrm{HCl}$ to ensure that the sensor would not be affected by $\mathrm{pH}$ changes.

\section{Instrumentation for the hydrogen sensor}

The electrical circuit (Fig. 2) was designed to generate a polarizing potential of DC $550 \mathrm{mV}$ between the Pt-Pt black anode (sensing electrode) and the $\mathrm{Ag}-\mathrm{AgCl}$ cathode (counter electrode) to achieve hydrogen oxidation (Kuroda et al., 1991; Niedrach and Stoddaed, 1982). The polarizing potential was continuously monitored by a digital multi tester, model 7532-01 (YOKOGAWA Instruments Co., Ltd., Tokyo) with a high input impedance of more than $10 \mathrm{M} \Omega$. The output current from the sensor was converted into a voltage signal by a $101.3 \Omega$ resistor and the voltage value recorded on a recorder, PRP-5021 (TOA Electronics Ltd., Tokyo) with a high input impedance of more than $1 \mathrm{M} \Omega$.

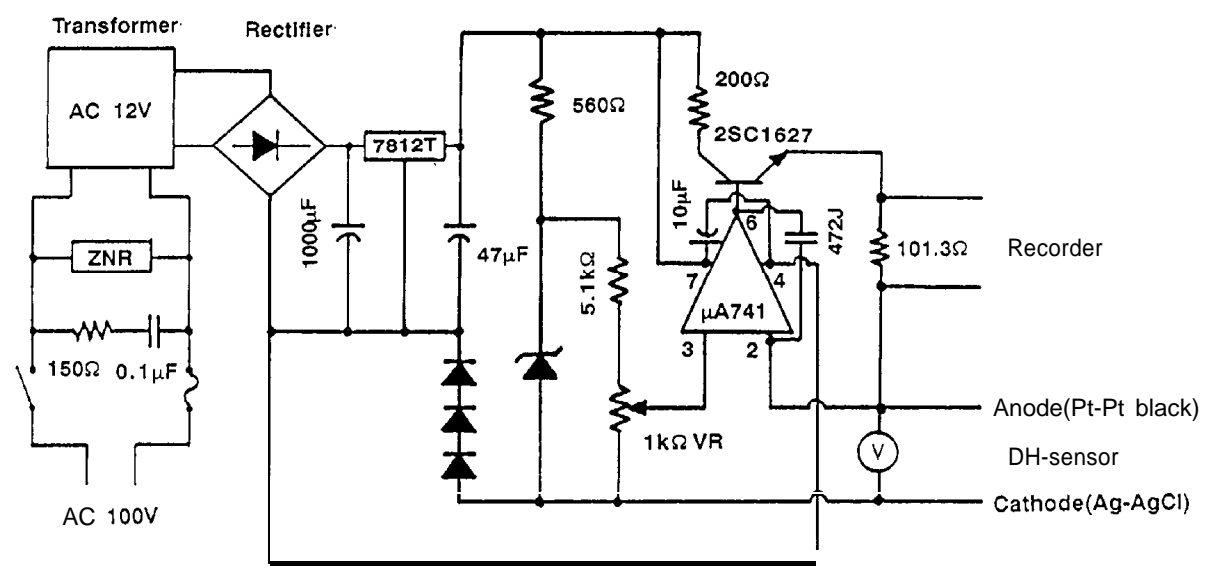

Fig. 2. Schematic diagram of the circuit for the dissolved hydrogen sensor. 


\section{Dissolved oxygen sensor}

The partial pressure of dissolved oxygen was measured with a galvanic oxygen sensor, 10AN-S, and a dissolved oxygen meter, Al-1007 (Biott Co. Ltd., Tokyo). The output voltage from the meter was recorded on the same PRP-5021 recorder used for the hydrogen sensor.

\section{D etermination of $\left(\boldsymbol{K}_{\mathrm{I}} \boldsymbol{a}\right)_{\mathrm{H} 2}$ by dynamic gassing out and steady state method}

The overall volumetric coefficient of hydrogen mass transfer was determined during the autotrophic batch culture of A. eutrophus ATCC $17697^{\mathrm{T}}$. When the dry cell weight reached $8.0 \mathrm{~g} / \mathrm{l}$ the gas supply was suspended and the agitation speed lowered to $250 \mathrm{rpm}$ indicated as 'gas off' in Fig. 3. The gas supply was resumed and the agitation speed returned to normal before the dissolved hydrogen partial pressure reached the critical (limiting hydrogen uptake) value - indicated as 'gas on' in Fig. 3. The change in the dissolved hydrogen partial pressure was recorded by the dissolved hydrogen sensor. Because the hydrogen consumption rate was constant throughout the gassing out stage the following relationship describes the hydrogen consumption rate during this stage:-

$$
R_{\mathrm{H} 2}=H_{\mathrm{H} 2} \cdot\left(P_{\mathrm{LB}}-P_{\mathrm{L}}\right) / t
$$

At steady state dissolved hydrogen concentration, the hydrogen consumption rate equals the hydrogen transfer rate into solution, thus:-

$$
\&=\left(K_{\mathrm{L}} a\right)_{\mathrm{H} 2} \cdot H_{\mathrm{H} 2} \cdot\left(P_{\mathrm{G}}-P_{\mathrm{LB}}\right)
$$

Thus, the overall volumetric coefficient of hydrogen mass transfer in the biological system, $\left(K_{\mathrm{I}} a\right)_{\mathrm{H} 2}$, can be calculated from the following equation:-

$$
\left(K_{\mathrm{l}} a\right)_{\mathrm{H} 2}=\left(P_{\mathrm{LB}}-P_{\mathrm{L}}\right) /\left\{\left(P_{\mathrm{G}}-P_{\mathrm{LB}}\right) \quad 0 \quad t\right\}
$$

\section{D etermination of $\left(\boldsymbol{K}_{\mathrm{I}} \boldsymbol{a}\right)_{\mathrm{O} 2}$}

The overall volumetric coefficient of oxygen mass transfer in the fermentor was determined by using the sulphite oxidation method $\left[\left(K_{\mathrm{L}} a\right)_{\text {Ozsul. }}\right]$ and by the dynamic gassing out and steady state method $\left[\left(K_{\mathrm{L}} a\right)_{\text {Oabiol }}\right]$.

\section{D etermination of the critical partial pressure of dissolved hydrogen and oxygen}

The critical partial pressure of dissolved hydrogen and oxygen for A. eutrophus

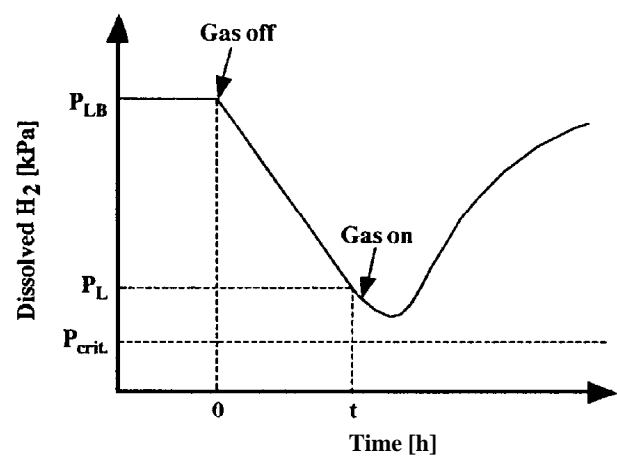

Fig. 3. Change in partial pressure of dissolved hydrogen during the determination of the hydrogen consumption rate. 
ATCC $17697^{\mathrm{T}}$ were determined by terminating the gas supply to the culture and recording the decline in the concentrations of the dissolved gasses. The gas composition fed to the reactor was adjusted to achieve either hydrogen or oxygen limitation after termination of the gas supply. Oxygen limitation was achieved by using a gas composition of $\mathrm{H}_{2}: \mathrm{O}_{2}: \mathrm{CO}_{2}: \mathrm{N}_{2}$ of 8:1:1:0 whilst hydrogen limitation was achieved using a composition of $4: 2: 1: 3$, respectively.

\section{RESULTS AND DISCUSSION}

\section{Characteristics of the hydrogen sensor}

The hydrogen sensor was calibrated using hydrogen dissolved in distilled water. Output currents from the hydrogen sensor at various partial pressure of hydrogen are shown in Fig. 4. When dissolved hydrogen was removed from distilled water by sparging with nitrogen, the output current from the sensor was $205 \mathrm{nA}$. The output current generated by the sensor under hydrogen saturated conditions was $28.4 \mu \mathrm{A}$. The correlation coefficient of the linear relationship in Fig. 4 is 0.999.

Although sulphite compounds are known to affect the current output of hydrogen sensors (Kuroda et al., 1991) it was confirmed that none of the ingredients used in the culture medium interfered with the probe response.

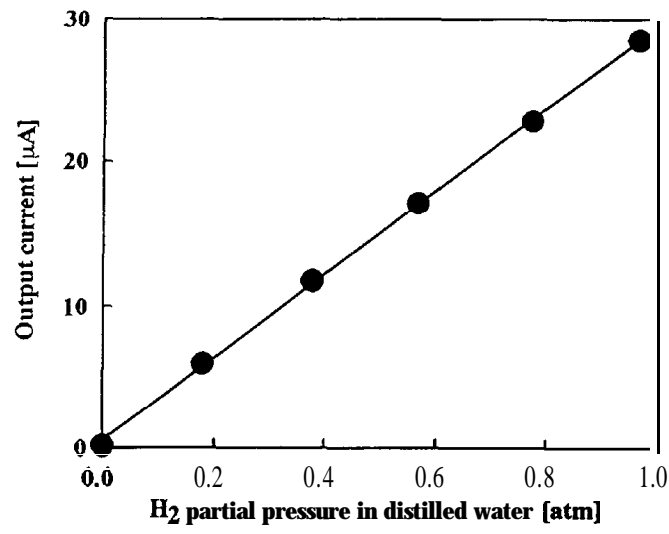

Fig, 4. Calibration of the assembled dissolved hydrogen sensor.

Table 1. The volumetric mass transfer coefficients $\left(\mathrm{h}^{-1}\right)$.

Agitation (rpm)

\begin{tabular}{cccc} 
& 1100 & 1400 & 1700 \\
\hline$\left(K_{\perp} a\right)_{\text {Oasal }}$ & 257 & 319 & 417 \\
$\left(K_{\mathbf{L}} a\right)_{\text {Otiol }}$ & 385 & 558 & 716 \\
$\left(K_{\perp} a\right)_{\text {Hz }}$ & 628 & 847 & 1430
\end{tabular}




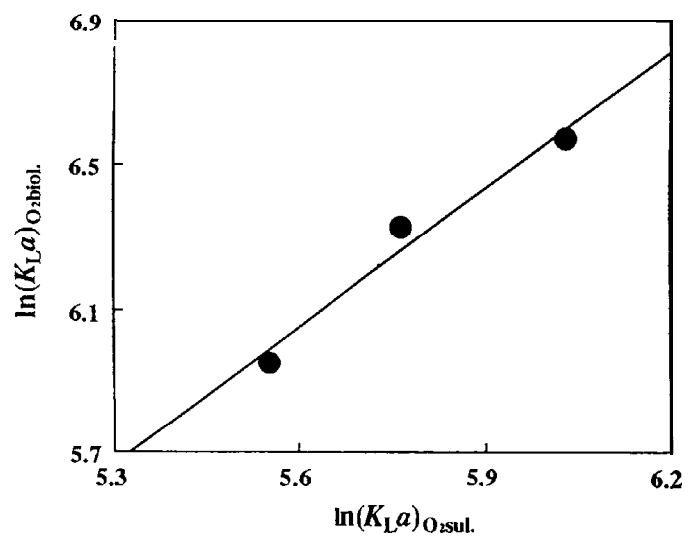

Fig. 5. Relationship between $\left(K_{\mathrm{L}} a\right)_{\text {O2biol. }}$ and $\left(K_{\mathrm{L}} a\right)_{\text {Ozbiol. }}$

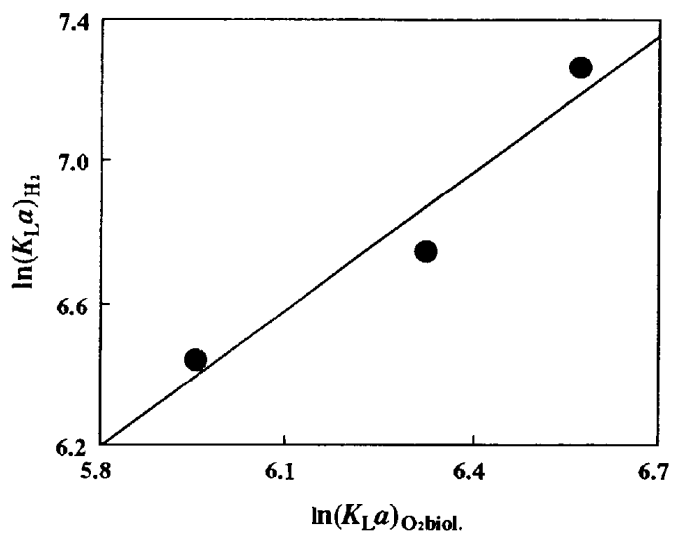

Fig. 6. Relationship between $\left(K_{\mathrm{L}} a\right)_{H 2}$ and $\left(K_{\mathrm{L}} a\right)_{\text {O2biol. }}$

\section{0 verall volumetric coefficients of hydrogen and oxygen mass transfer}

$\left(K_{\mathrm{L}} a\right)_{\mathrm{H} 2},\left(K_{\mathrm{L}} a\right)_{\text {O2sul }}$ and $\left(K_{\mathrm{L}} a\right)_{\text {ozbiol }}$ were determined at agitation speeds of 1100,1400 and $1700 \mathrm{rpm}$. The results of these determinations were shown in Table 1. For oxygen, the $K_{\llcorner} a$ value determined using the dynamic gassing out and steady state method, $\left(K_{\mathrm{L}} a\right)_{\text {obbiol }}$ was larger than the value obtained using the sulphite oxidation method, $\left(K_{\mathrm{L}} a\right)_{\text {o2sil, }}$ a phenomenon also reported (Hsieh et $a l$. , 1969). The $\left(K_{\mathrm{L}} a\right)_{\mathrm{H} 2}$ value was higher than that of the $\left(K_{\mathrm{L}} a\right)_{\text {ozbiol }}$, supporting similar date (Kodama et al., 1976) generated from microorganism-free media.

The relationship between the overall volumetric coefficients for oxygen detemined by the sulphite method and the dynamic gassing out and steady state method is shown in the natural logarithm plot of the two factors (Fig. 5). This graph indicates a linear relationship between the natural logarithms of the differently determined $K_{\mathrm{L}} a$ 's, expressed in equation (4) with a correlation coefficient of 0.970 . The relationship between $\left(K_{\mathrm{L}} a\right)_{\mathrm{H} 2}$ and $\left(K_{\mathrm{L}} a\right)_{\text {Orbio? }}$ is shown in Fig. 6, the linear relationship between the natural logarithms of the $K_{\mathrm{L}} a$ values being expressed by equation (5) at a correlation coefficient of 0.930 . 

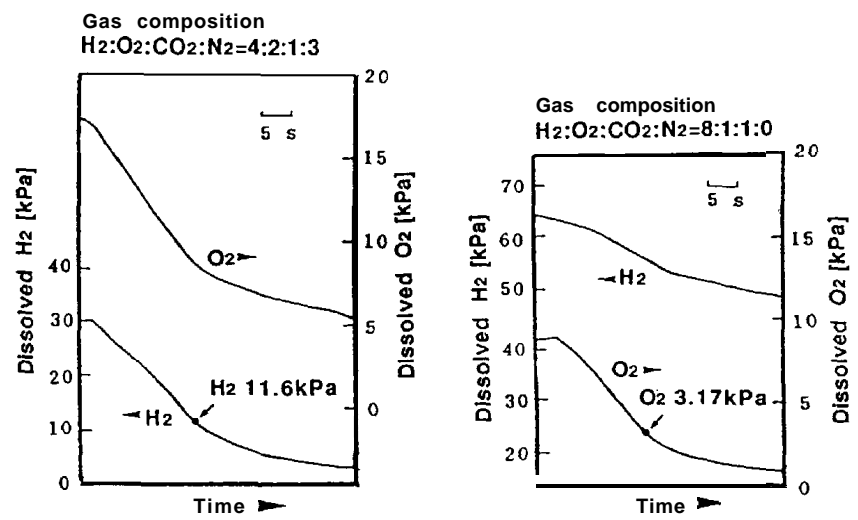

Fig. 7. Determination of the critical partial pressure for dissolved hydrogen (left) and dissolved oxygen (right) in autotrophic batch A. eutrophus.

Table 2. The volumetric absorption coefficients.

\begin{tabular}{|c|c|c|c|}
\hline & \multicolumn{3}{|c|}{ Agitation (rpm) } \\
\hline & 1100 & 1400 & 1700 \\
\hline$(K d)_{\mathrm{H} 2}$ & $4.70 \cdot 10^{-3}$ & $6.34 \cdot 10^{-3}$ & $1.07 \cdot 10^{-3}$ \\
\hline$(K d)_{\varnothing}$ & $4.43 \cdot 10^{-3}$ & $6.42 \cdot 10^{-3}$ & $8.23 \cdot 10^{-3}$ \\
\hline & $\begin{array}{l}=0.347\left(K_{\perp}\right. \\
0.280\left(K_{\mathrm{L}} a\right.\end{array}$ & sul 1.27 & \\
\hline
\end{tabular}

Critical partial pressure of dissolved hydrogen and oxygen

The uptake of dissolved oxygen and hydrogen by cultures of $A$. eutrophus after termination of the gas supply is shown in Fig. 7. Either oxygen or hydrogen limitation was induced after gas termination by the composition of the gas supply, as indicated in the methods section. From Fig. 7 it may be seen that the critical partial pressure of dissolved hydrogen was much greater than that for oxygen $-11.6 \mathrm{kPa}$ for hydrogen compared with $3.17 \mathrm{kPa}$ for oxygen. The ratio of the critical partial pressure of dissolved hydrogen to that of oxygen is 3.66. It is interesting to note that this ratio agrees well with the molar ratio of hydrogen to oxygen, 3.44 , calculated from the stoichiometric requirements of the organism.

The volumetric absorption coefficients of the two gasses $(K d)_{\mathrm{H} 2}$ and $(K d)_{\mathrm{O} 2}$ were calculated as the product of the relevant $K_{\mathrm{L}} a$ and Henry's constant. From Table 2 it may be seen that the $K d$ values for hydrogen and oxygen are very similar despite the fact that the $K_{1} a$ values for hydrogen were greater than those for oxygen. This may be explained by the Henry's constant for hydrogen being lower than that for oxygen.

To ensure the safe operation of the process it is essential that the composition of the gas phase is strictly controlled to ensure that the ratio of oxygen to hydrogen is not within the detonation range. Using a modified Hempel's method we have demonstrated 


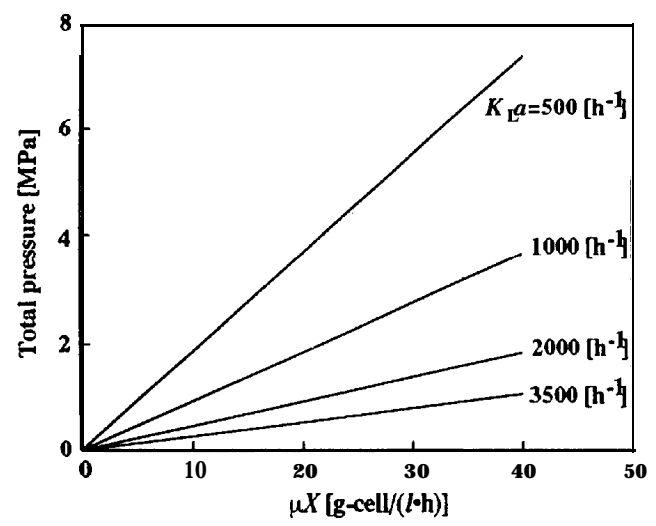

Fig. 8. Relationship between productivity, gas pressure and mass transfer capacity.

that the highest safe concentration of oxygen in a gas mixture of hydrogen, oxygen, carbon dioxide and water was $6.9 \%$. Thus, to allow a reasonable safety margin, the oxygen concentration in the gas mixture should not exceed 6\%. Since the critical partial pressure of dissolved oxygen for the organism is $3.17 \mathrm{kPa}$ the maximum transfer rate attainable can be represented by the equation:-

$$
\left(K_{\mathrm{I}} a\right)_{\text {Orbiol }} \cdot H_{\propto 2}(0.06 P-3.17)=\mu X / Y_{\mathrm{O}}
$$

where $Y_{O 2}$ is 15.7 calculated from the stoichiometry previously published (Ishizaki and Tanaka, 1990). The relationship between $\left(K_{\llcorner} a\right)_{\text {obbiol }}, P$ and $\mu X$ is shown in Fig. 8. As may be seen from this figure high cell productivity may be achieved by either increasing the $\left(K_{\mathrm{L}} a\right)_{\text {orsiol }}$.or increasing the head pressure in the vessel, $P$. We constructed a high $K_{\mathrm{L}} a$, explosion-proof bench fermentor equipped with a specially designed agitator and, using this vessel, we obtained high productivity under safe operating conditions for the full duration of the fermentation (Chem. Eng. in press). However, it should be remembered that PHB accumulation occurs under oxygen limitation and, therefore, the oxygen supply must be controlled to achieve a zero dissolved oxygen concentration during the production phase. Thus, whilst it is difficult to obtain high biomass productivity under safe conditions there is very little danger of detonation during the PHB production phase of the fermentation. We are now investigating the feasibility of a two-stage fermentation employing heterotrophic growth using carbohydrate and air for biomass production followed by autotrophic conditions under oxygen limitation for PHB synthesis therefore eliminating the risk associated with a hydrogen process. We are also investigating the behavior of the organism under hydrogen limitation. These results will be published in the near future.

\section{ACKNOWLEDGEMENT}

The authors express their sincere appreciation to Y. Ishikawa of Biott Co. Ltd. for providing the electrode materials and technical support. 


\section{NOMENCLATURE}

$H_{\mathrm{H} 2}$ : Henry's constant for hydrogen at $30^{\circ} \mathrm{C}$,

$\left(7.49 \cdot 10^{-6}\right) \mathrm{mol} / 1 \cdot \mathrm{kPa}$

$H_{\propto 2}$ : Henry's constant for oxygen at $30^{\circ} \mathrm{C}$,

$\left(1.15 \cdot 10^{-5}\right) \mathrm{mol} / 1 \cdot \mathrm{kPa}$

$(K d)_{\mathrm{Hz}}:$ Volumetric absorption coefficient for hydrogen, $\mathrm{mol} / \mathrm{l} \cdot \mathrm{kPa} \cdot \mathrm{h}$

$(K d)_{\alpha 2}$ Volumetric absorption coefficient for oxygen, $\mathrm{mol} / \mathrm{l} \cdot \mathrm{kPa} \cdot \mathrm{h}$

$\left(K_{\iota} a\right)_{\mathrm{H} 2}$ : Overallvol umetric coefficient of hydrogen mass transfer in biological system, $1 / \mathrm{h}$

$\left(K_{\mathrm{L}} a\right)_{\text {Oobiol. }}$ Overall volumetric coefficient of hydrogen mass transfer in biological system, $1 / \mathrm{h}$

$\left(K_{\llcorner} a\right)_{\text {ossul: }}$ Overall volumetric coefficient of oxygen mass transfer in sulfite oxidation system, $1 / \mathrm{h}$

$P$ : Head pressure in a fermentor, $\mathrm{kPa}$

$P_{\text {crit: }}$ Critical partial pressure of dissolved hydrogen, $\mathrm{kPa}$

$P_{\mathrm{G}}$ : Partial pressure of hydrogen in exhaust gas, $\mathrm{kPa}$

$P_{\mathrm{L}}$ : Partial pressure of dissolved hydrogen at gas on, $\mathrm{kPa}$

$P_{\mathrm{LB}}$ : Partial pressure of dissolved hydrogen at gas off, $\mathrm{kPa}$

$P_{\mathrm{Hz}:}$ Hydrogen consumption rate,

$t:$ Time, h

$X$ : Dry cell weight, g-cell

$Y_{\mathrm{O} 2}$ : Growth yield factor based on oxygen, g-cell

$\mu$ : Specific growth rate, $1 / \mathrm{h}$

\section{REFERENCES}

Doi, Y., A., Tamaki, M., Kunioka and K., Soga 1988 Production of 3-hydroxybutylate and 3 - hydroxyvalerate by Alcaligenes eutrophus from butyric and pentanoic acids. Appl. Microbiol. Biotechnol., 28: 330 -334

Heinzle, E. and R. M., Laffety 1980 Continuous mass spectrometric measurement of dissolved $\mathrm{H}_{2}$, $\mathrm{O}_{2}$, and $\mathrm{CO}_{2}$ during chemolithoautotrophic growth of Alcaligenes eutrophus strain $\mathrm{H}$ 16. Eur.J. Appl. Microbial. Biotechnol., 11: 17-22

Hsieh, D. P. H., R. S., Silver and R. I., Mateles 1969 Use of the glucose oxidase system to measure oxygen transfer rates, Biotech. Bioeng., 11: 1-18

Ishizaki, A. and Y., Hirose 1973 Kinetics of carbon dioxide evolution in agitation system. Agr. Biol. Chem., 37: 1295-1305

Ishizaki, A., H., Shibai, Y., Hirose and T., Shiro 1973 Estimation of aeration and agitation conditions in respect to oxygen supply and ventilation. Agr.Biol. Chem., 37: 107-113

Ishizaki, A. and K. Tanaka 1991 Production of poly $-\beta$ hydroxybutyric acid from carbon dioxide by Alcaligenes eutrophus ATCC $17697^{\mathrm{T}}$. J. Ferment. Bioeng., 71: 254-257

Ishizaki, A. and K., Tanaka 1990 Batch culture of Alcaligenes eutrophus ATCC $17697^{\mathrm{T}}$ using recycled gas closed circuit culture system. J. Ferment. Bioeng., 69: 170-174 
Kodama, T., E. Goto and Y. Minoda 1976 Determination of dissolved hydrogen concentration and in submerged culture vessel. Agr. Biol. Chem., 40: 2373-2377

Kunioka, M., Y. Kawaguchi and Y. Doi 1989 Production of biodegradable copolysters of 3 hydroxybutylate and 4 -hydroxybutylate by Alcaligenes eutrophus. Appl.Microbiol. Biotecnol., 30: $569-573$

Kuroda, K., R. G. Silveira, N. Nishio, H. Sunahara and S. Nagai 1991 Measurement of dissolved hydrogen in an anaerobic digestion process by a membrane-covered electrode. J. Ferment. Bioeng., 71: 418-423

Kurosawa, K. and B. hagihara 1986 Measurement of oxygen and hydrogen by polarograohic method. Taisya, 23: 555-561

Niedrach, L. W. and W. H. Stoddard 1982 Continuous voltametric monitoring of hydrogen and oxygen in water. Anal. Chem, 54: 1651-1654

Ohi, K., T. Nishimura, M. Okazaki and Y. Miura 1979 Determination of dissolved hydrogen concentration during cultivation and assimilation of gaseous substrates by Alcaligenes hydrogenophilus. J. Ferment. Technol., 57: 203-209

Pauss, A., R. Samson, S. Guiot and C. Beauchemin 1990 Continuous measurement of dissolved $\mathrm{H}_{2}$ in an anaerobic reactor using a new hydrogen/air fuel cell detector. Biotechnol. Bioeng., 35: 492-501

Siegel, R. S. and D. F. Ollis 1984 Kinetics of growth of the hydrogenoxidizing bacterium Alcaligenes eutrophus (ATCC 17707) in chemostat culture. Biotechnol. Bioeng., 26: 764-770

Sweet, W. J., j. P. Houchins, P. R. Rosen and D. J. Arp, 1980 Polarograohic measurement of $\mathrm{H}_{2}$ in aqueous solution. Anal. Biochem., 107: 337-340 